\title{
Standard set of health outcome measures for older persons
}

\author{
Asangaedem Akpan ${ }^{1 *}$ (D) Charlotte Roberts ${ }^{2,3}$, Karen Bandeen-Roche ${ }^{4}$, Barbara Batty ${ }^{5}$, Claudia Bausewein ${ }^{6}$, \\ Diane Bell1 ${ }^{7}$, David Bramley ${ }^{8}$, Julie Bynum ${ }^{9}$, Ian D. Cameron ${ }^{10}$, Liang-Kung Chen ${ }^{11,12}$, Anne Ekdahl ${ }^{13}$, Arnold Fertig ${ }^{14}$, \\ Tom Gentry ${ }^{15}$, Marleen Harkes ${ }^{16}$, Donna Haslehurst ${ }^{17}$, Jonathon Hope ${ }^{32}$, Diana Rodriguez Hurtado ${ }^{18}$, \\ Helen Lyndon ${ }^{8}$, Joanne Lynn ${ }^{19}$, Mike Martin ${ }^{20}$, Ruthe Isden ${ }^{15}$, Francesco Mattace Raso ${ }^{21}$, Sheila Shaibu ${ }^{22}$, \\ Jenny Shand ${ }^{23}$, Cathie Sherrington ${ }^{24}$, Samir Sinha ${ }^{25,26}$, Gill Turner ${ }^{27}$, Nienke De Vries ${ }^{28}$, George Jia-Chyi Yi ${ }^{29}$, \\ John Young ${ }^{8,30}$ and Jay Banerjee ${ }^{31}$
}

\begin{abstract}
Background: The International Consortium for Health Outcomes Measurement (ICHOM) was founded in 2012 to propose consensus-based measurement tools and documentation for different conditions and populations. This article describes how the ICHOM Older Person Working Group followed a consensus-driven modified Delphi technique to develop multiple global outcome measures in older persons.

The standard set of outcome measures developed by this group will support the ability of healthcare systems to improve their care pathways and quality of care. An additional benefit will be the opportunity to compare variations in outcomes which encourages and supports learning between different health care systems that drives quality improvement. These outcome measures were not developed for use in research. They are aimed at non researchers in healthcare provision and those who pay for these services.
\end{abstract}

Methods: A modified Delphi technique utilising a value based healthcare framework was applied by an international panel to arrive at consensus decisions.To inform the panel meetings, information was sought from literature reviews, longitudinal ageing surveys and a focus group.

Results: The outcome measures developed and recommended were participation in decision making, autonomy and control, mood and emotional health, loneliness and isolation, pain, activities of daily living, frailty, time spent in hospital, overall survival, carer burden, polypharmacy, falls and place of death mapped to a three tier value based healthcare framework.

Conclusions: The first global health standard set of outcome measures in older persons has been developed to enable health care systems improve the quality of care provided to older persons.

Keywords: Older people, Health outcomes

\section{Background}

The number of older people and their life expectancy has been rising steadily ranging from 50 years in resource poor to 83 years in resource rich regions [1]. Older people commonly have more than one chronic condition and have frequent encounters with healthcare providers [2]. Provision of care can be fragmented due to multiple

\footnotetext{
* Correspondence: asan.akpan@aintree.nhs.uk

${ }^{1}$ Department of Medicine for the Elderly, Aintree University Hospital NHS

Foundation Trust, Lower Lane, Liverpool L9 7AL, UK

Full list of author information is available at the end of the article
}

assessments and treatments [3]. While focusing on a single condition may have advantages, a holistic approach with a review of outcomes that matter has greater value. Variation in outcomes of healthcare is a global challenge [4] and having the proposed set of outcome measures will facilitate and support reducing this variation.

Understanding what outcomes matter to patients would be valuable to clinicians and policymakers in aligning health care services to their needs. The aim of this project was to define a minimum set of outcomes for evaluating healthcare for older people. A Delphi technique was used 
to develop a balanced score card that was feasible to implement in routine clinical practice. An additional goal was to facilitate the creation of databases that can be compared and/or merged for analysis. This would support decision making being shared between providers, facilitate quality improvement and allow for benchmarking across organisations and countries.

The lack of outcome measurements that matter most to patients represents a barrier to health care improvement [5] and means providers have little information on which to judge the effectiveness of interventions. The ICHOM has to date developed 13 standard sets of outcome measures [6] and by 2017 at least $50 \%$ of the global disease burden will be covered. ICHOM (www.ICHOM.org) was founded in 2012 to promote value-based health care by defining global standard sets of outcome measures that matter to patients and promote adoption of these measures worldwide. This would be ICHOM's first standard set of outcomes for a population as opposed to a specific condition such as cataracts, dementia or lung cancer [6].

ICHOM is a non-profit organisation supported by the Harvard Business School, Boston Consulting Group and the Karolinska Institute to transform health care systems worldwide by measuring and reporting patient outcomes in a standardised way. ICHOM organises global teams of physician leaders, outcomes researchers and patient advocates to define Standard Sets of outcomes per medical condition, and then drives adoption to enable health care providers globally to compare, learn, and improveA working group (WG) was organised by ICHOM, to represent a wide clinical, scientific and cultural background. Members $(n=31)$ included patient representatives, measurement experts, clinical, social and psychological researchers. Countries represented included Australia, Botswana, Canada, Germany, The Netherlands, Sweden,
Switzerland, Taiwan, Peru, the United Kingdom, and the United States of America.

\section{Method}

A modified Delphi technique was used to develop the standard set. The Delphi technique is an iterative, multistage process to actively transform opinion into group consensus [7]. Over a period of 10 months, the working group met eight times over teleconferences.

The goals and scope of the working group were discussed in the first teleconference. The second to fourth teleconferences (call 1 to 3 in Fig. 1) focused on the outcome domains and definitions to include in the standard set. In preparation for teleconferences 2-4, the working group were provided with information from literature reviews (Additional file 1: Table S1) and an older person's and carer focus groups (Table 1). ICHOM organised an older people focus group with six attendees (age range 68-89) after the working group launch, to obtain their perspectives, using open-ended questions. Participants, consulted through Age UK's networks, discussed which outcomes were of greatest importance to them. Age UK (http://www.ageuk.org.uk) is a charity dedicated to improving the lives of older people via a national network supported and facilitated by partnerships.

To support the decision making process the working group used a set of 4 criteria; represent the end results or 'outcomes' of care, represent what is important to OP and their families, feasible to capture and can be used for quality improvement programmes.

The discussion content was collated into online surveys. Working group members were asked to submit their feedback and votes via a web survey questionnaire. The survey had all the outcomes discussed with the level of agreement ranked during the teleconferences. Decisions resulting from the surveys required a minimum

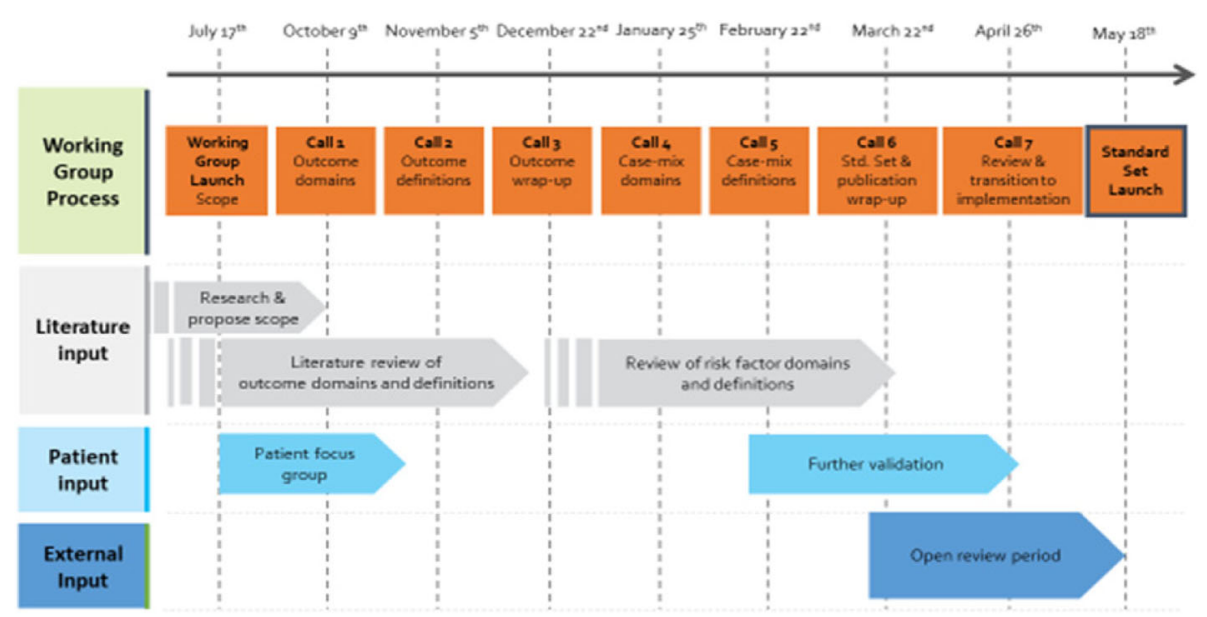

Fig. 1 Showing the process and timeline for the working group. A flow chart showing the working group process 
Table 1 Themes from the older persons and carer focus group

\begin{tabular}{|c|c|}
\hline $\begin{array}{l}\text { Amongst many discussed, the } \\
\text { groups felt the following were most } \\
\text { important: }\end{array}$ & $\begin{array}{l}\text { However, there were a few new } \\
\text { topics and points to consider: }\end{array}$ \\
\hline $\begin{array}{l}\text { - Social and community participation } \\
\text { - Independence and remaining in } \\
\text { own home } \\
\text { - Quality of life and wellbeing } \\
\text { - Avoiding inappropriate discharges } \\
\text { and readmissions } \\
\text { - Isolation } \\
\text { - Loneliness and friendship } \\
\text { - Physical disabilities - hearing, } \\
\text { vision, continence, mobility } \\
\text { - Hobbies and activities } \\
\text { - Access to } 24 \text { h healthcare and } \\
\text { social services } \\
\text { - Avoiding falls } \\
\text { - Delaying frailty } \\
\text { - Care and respite for the carer } \\
\text { - Malnutrition, weight loss and } \\
\text { appetite } \\
\text { - Physical symptom burden } \\
\text { - Pain } \\
\text { - Sleep quality }\end{array}$ & $\begin{array}{l}\text { - Survival/mortality was seen as } \\
\text { being less important than other } \\
\text { outcomes - instead seen as } \\
\text { inevitable and expected } \\
\text { - Role in society e.g. formal/ } \\
\text { informal job or volunteering } \\
\text { - Consistency of medical service/ } \\
\text { single coordinator of care }\end{array}$ \\
\hline
\end{tabular}

$50 \%$ of the working group membership participation. It was anticipated that due to time zone differences and schedules, this was a practical and reasonable standard to adopt given a fixed deadline by which the work had to be completed.

Teleconferences 5 and 6 (calls 4 and 5 Fig. 1) addressed case mix factors and definitions. Teleconferences 7 and 8 (calls 6 and 7 Fig. 1) focused on reviewing the agreed outcome domains, case mix factors and how the standard set would be shared with the healthcare community. Over the 10 months of the project, attendance for the teleconference meetings ranged between $51.7 \%$ to $75.9 \%$ (mean $61.1 \%$ ). Three voting surveys were conducted with varying response rates. For a measure to be accepted as an outcome the working group set a standard of $70 \%$ and above of members voting to include a measure as an outcome.The final standard set was approved by all members of the working group.

PRISMA reporting principles were used as guidance for the literature search strategy [8]. Titles, keywords and abstracts were searched using MeSH or equivalent terms in the following databases PubMed/Medline, EMBASE, Psychinfo, Social Care online, Cumulative Index to Nursing and Allied Health Literature (CINAHL), COCHRANE, PsychInfo. Inclusion criteria included: (Aged, 80 and over OR Frail elderly or Comorbidity) AND (quality of life OR outcome assessment (healthcare) OR quality indicators), Paper and guidelines reporting on patient-reported and patient-centred outcomes, English language abstracts, reviews and randomised controlled trial,2005 onwards. Exclusion criteria included Non-English language, irretrievable, insufficient outcome data, unclear diagnoses, unvalidated outcomes.
Additional sources of information included existing measurement approaches adopted by longitudinal ageing surveys [9-38]. Figure 1 summarises the working group process.

Triangulating findings from the literature review and focus group with the working group discussions would strengthen the resultant outcome measures decided upon and highlight the key issues that most matter to older people. Experience of and satisfaction with care by older people and their carers including distress and mood was noted in quality of life literature reviews but did not come up specifically in the focus group discussions.

A three tiered hierarchy framework [39] has been utilised to categorise the outcome measures. Tier 1 is the health status achieved or retained with survival and then degree of recovery achieved. Tier 2 is the process of recovery with time to recovery and return to normal activities as well as the treatment burden such as side effects and complications.Tier 3 is sustainability of health with recurrences and long term consequences of care interventions.

A specific cut off age was considered inappropriate due to the range in life expectancies around the world. During the working group discussions, it was agreed that the last 10 years of life captured a period in which a person might be regarded as being old across the world and potentially seeking healthcare. Therefore, rather than specifying a fixed cut-off age as the inclusion population for this standard set, the working group recommended subtracting 10 years from the estimated life expectancy at 60 years in each country or region. The inclusion population would be those who are at or above this age. For example, in South Africa, the life expectancy at age 60 is 76 years old, therefore the inclusion population would be all those over the age of 66 [40-43]. These can be utilised for any society in the world where a particular age is viewed as old if it does not fall within the definition above. The principles that apply to older people would be the same. This respects and accepts that each society can define what old age is to them.

\section{Results}

The suggested initial outcomes were chosen based on congruency across findings from the registries, surveys, literature searches and engagement with older people. A minority were chosen based on the consensus experience of the working group members. In the general category health status, quality of life, mortality, independence, remaining at home, carer health, and autonomy were deemed essential. In physical health, functional status, symptom occurrence, sleep, harm, frailty stage, nutrition, weight loss was also essential. Mental and psychological health had cognition, mood and loneliness as essential. Social network, support and isolation were essential in the social and community category. Length of stay, care 
coordination and discharge to place of choice were essential in healthcare utilisation. Dignity, shared decision making, access to information and advice were deemed essential under the experience/process category.

Tier 1 outcomes were overall survival, frailty and place of death. Tier 2 outcomes were polypharmacy, falls, participation in decision making and time spent in hospital. Tier 3 outcomes included loneliness and isolation, activities of daily living, pain, mood and emotional health, autonomy and control and carer burden. The results of the voting outcomes are summarised in Tables 2, 3, 4 and 5 summarises the outcome measures mapped to the tiers.

The collection of a minimum set of baseline characteristics is recommended to allow case-mix adjustments $[44,45]$ Case-mix adjustment is a useful and fair way for making comparisons among health care providers. Taking these into consideration reduces disadvantages in comparative ratings due to differences in the underlying population of interest.

The working group agreed:

a) Demographic factors: Such as age, gender, level of education, living arrangements, marital status and ethnicity. Items are harmonised to other ICHOM surveys. The educational level should be assessed following the International Standard Classification of Education [46] to allow global comparisons.

b) Condition specific variables: These were frailty stage, type of medication used, total number of medications and baseline cognition.

c) Systemic variables: Included were co-morbidities, smoking, alcohol use, weight, height, body mass index, vision and hearing impairment, and baseline activities of daily living.

A reference guide is freely available online that further describes the recommended instruments, data sources and provides detailed information (www.ichom.org).

\section{Discussion}

A standard set of outcome measures that matter to older people has been developed by a global panel of interdisciplinary professionals,older people and their carers.

The strengths of this project include the global interdisciplinary collaboration, involving older people and their carers and triangulating findings from a focus group, professional experience and the published literature. Obtaining information from various sources was important as not surprisingly not all domains were articulated in the single focus group due to its small sample. This also focused on a subset of a population rather than on a specific medical condition. To date no other set of outcome measures for older people has been developed using this approach. This approach has reduced the chances of excluding important themes that matter to older people. In attempting to be comprehensive and for the findings to be feasible for implementation, some themes had to be excluded. This does not mean they are not important but feasibility of the outcomes being used was regarded by the working group to be critical. The outcome measures have not been developed for use by academic researchers and will therefore not meet criteria for use by that group. The measures have been specifically developed for practical use by healthcare providers and those who pay for these services.

The framework utilised to develop these outcomes is based on Porter's outcome hierarchy [39]. Tier 1 is the most important with the outcome being survival or the best possible state achieved for a condition. Tier 2 outcomes are the issues related to achieving tier 1 outcomes such as the time to recovery from a flare up of a chronic disease or recovery from an acute disease. Included in this tier 2 are all the harms associated with investigations and treatment. Tier 3 outcomes relate to long term health status.

Healthcare providers should appreciate and understand the perception, attitude and behaviour of those they care for [47]. In this context, "what matters to you" as a recipient of healthcare is more important than "what is the matter with you." We have attempted to balance the information derived from previous studies to compensate for this by incorporating the views of $\mathrm{OP}$ and their carers. We hope that whilst not ideal, concerted efforts were made to ensure that the voice of $\mathrm{OP}$ and their carers were incorporated.

The value of performance based measures including grip strength as health outcomes for older adults [48] was discussed. The evidence base supporting the value of such measures for providing integrative assessments of older persons' health, and for identifying persons at risk of a decline in health was recognized. The majority of the group considered the collection of such measures burdensome as part of a minimum set of indicators to be included in the standard set but endorse the value of incorporating them in specialty geriatric settings.

Frailty is well recognised $[49,50]$. For providers, understanding the proportion of those becoming frail will aid their future resource allocation, service planning and prevention strategies [51,52]. There was agreement for a frailty measure as a risk factor for outcome measure adjustment but much less agreement concerning the role of a frailty measure as a service outcome. Indeed, this was the most discussed topic. While the phenotype model [53] remains the gold standard for diagnosing frailty, the cumulative deficit model [54] was viewed by a majority as what clinicians will identify with more easily. Both have been validated in aiding clinical decision making $[48,55]$ and [56]. The Canadian Study of Health and Ageing (CSHA) Clinical Frailty Scale [43] was recommended as the tool to be used in the standard set to 
Table 2 Showing voting outcomes following round 1 survey of working group members. The $\%$ refers to the proportion of those who voted in support of each item

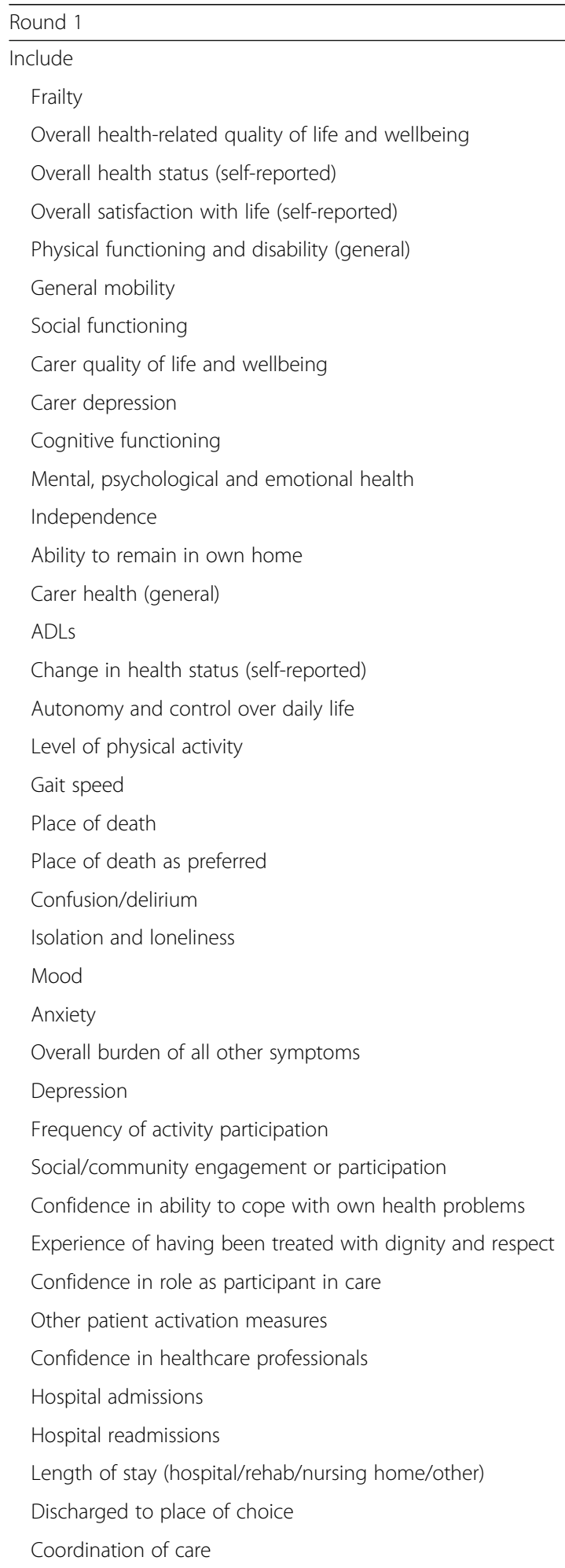

Table 2 Showing voting outcomes following round 1 survey of working group members. The \% refers to the proportion of those who voted in support of each item (Continued)

\begin{tabular}{|c|c|}
\hline Round 1 & Percent \\
\hline \multicolumn{2}{|l|}{ Inconclusive } \\
\hline Functional mobility & 58 \\
\hline Pain & 58 \\
\hline $\begin{array}{l}\text { Confidence in ability to access information and advice } \\
\text { when needed }\end{array}$ & 63 \\
\hline Confidence in ability to access appropriate healthcare & 68 \\
\hline Feeling safe (generally) & 68 \\
\hline Confidence in understanding of own health & 58 \\
\hline Falls resulting in a fracture & 58 \\
\hline Overall survival & 68 \\
\hline \multicolumn{2}{|l|}{ Excluded } \\
\hline Cause-specific survival & 27 \\
\hline Blood pressure & 15 \\
\hline Waist and hip circumference & 8 \\
\hline Heart rate & 15 \\
\hline Bone density & 15 \\
\hline Lung function & 12 \\
\hline Peak flow & 8 \\
\hline Aortic calcification & 12 \\
\hline Carotid intima-media thicknes & 8 \\
\hline Standing and sitting height & 12 \\
\hline Lean muscle mass and body composition & 23 \\
\hline Condition-specific outcomes & 15 \\
\hline Ability to work (formal/informal) & 46 \\
\hline Dynamic balance & 38 \\
\hline Static balance & 38 \\
\hline Lower-limb strength & 38 \\
\hline Grip strength & 38 \\
\hline Oral health & 42 \\
\hline Sleep quality & 38 \\
\hline Weight loss & 42 \\
\hline Appetite loss & 42 \\
\hline Stiffness & 27 \\
\hline Fatigue & 46 \\
\hline Medication adherence & 46 \\
\hline
\end{tabular}

assess frailty. It mirrors clinical judgement, is objective [57] and can be used in places with no electronic health records. However, alternative frailty tools may become widely implemented in some countries. For example, an electronic frailty index is now available for use for over $90 \%$ of general practitioners in England [58] (http://ageing.oxfordjournals. org/content/early/2016/03/03/ageing.afw039.full) and, an online tool (www.johnshopkinssolutions.com/solution/frailty) 
Table 3 Showing voting outcomes following round 2 survey of working group members. The \% refers to the proportion of those who voted in support of each item

\begin{tabular}{|c|c|}
\hline Round 2 & Percent \\
\hline \multicolumn{2}{|l|}{ Include } \\
\hline Functional mobility & 77 \\
\hline Pain & 72 \\
\hline Falls resulting in a fracture & 77 \\
\hline \multicolumn{2}{|l|}{ Inconclusive } \\
\hline $\begin{array}{l}\text { Confidence in ability to access information and advice } \\
\text { when needed }\end{array}$ & 50 \\
\hline Confidence in ability to access appropriate healthcare & 64 \\
\hline Feeling safe (generally) & 59 \\
\hline Confidence in understanding of own health & 55 \\
\hline Overall survival & 59 \\
\hline Overall burden of all physical symptoms & 59 \\
\hline Continence & 64 \\
\hline General experience of healthcare & 55 \\
\hline $\begin{array}{l}\text { Contact with healthcare (emergency service/doctor/ } \\
\text { nurse/outpatient clinic) }\end{array}$ & 50 \\
\hline Pressure ulcers & 50 \\
\hline Complications from treatment & 59 \\
\hline Adverse medication effects & 55 \\
\hline Falls resulting in seeking medical attention & 59 \\
\hline \multicolumn{2}{|l|}{ Excluded } \\
\hline Other palliative care specific outcomes & 41 \\
\hline Relationships & 68 \\
\hline Vision & 45 \\
\hline Hearing & 41 \\
\hline Sit to stand speed & 36 \\
\hline Number of falls & 68 \\
\hline Falls resulting in an admission to hospital & 68 \\
\hline
\end{tabular}

is available for frailty assessment utilising the phenotype model.

At first glance, polypharmacy, falls and length of stay in hospital may not appear to be outcome measures. This is where triangulation of findings from focus group and the working group discussions added value to this project. These three areas were things that mattered to older people, their carers and clinicians. It was felt that without keeping track of these in the form of outcome measures it could easily fall off the radar of health systems caring for older people. The SF-36 and other tools to capture the metrics around the outcome measures were chosen solely for very practical reasons. It had to be free to use and cover as many of the outcome measures to reduce the number of tools and complexity of use associated with this.
Table 4 Showing voting outcomes following round 3 survey of working group members. The \% refers to the proportion of those who voted in support of each item

\begin{tabular}{ll}
\hline Round 3 & Percent \\
\hline Include & 71 \\
Overall survival & 71 \\
Falls resulting in seeking medical attention & 75 \\
Polypharmacy (added in the third round) & \\
Inconclusive & 54 \\
Confidence in ability to access information and advice & \\
when needed & 63 \\
Confidence in ability to access appropriate healthcare & 58 \\
Confidence in understanding of own health & 54 \\
Complications from treatment & \\
Excluded & 42 \\
Feeling safe (generally) & 38 \\
Feeling safe within a healthcare organisation (added & \\
in the third round) & 46 \\
Overall burden of all physical symptoms & 38 \\
Continence & 29 \\
General experience of healthcare & \\
Contact with healthcare (emergency service/doctor/ & 38 \\
Pressure ulcers & 46 \\
Adverse medication effects & 46 \\
\hline
\end{tabular}

The final set of outcome measures arrived at has been reduced down from the original set at the outset of the project. In settling for a cut off, the working group applied feasibility and comprehensiveness as a guiding principle. In using such a diverse group, it is hoped that a reasonable balance has been struck.

The working group consensus was to measure the standard set outcomes longitudinally over time. A minimum annual frequency was recommended given the challenges of measurement and capturing population level changes. It was acknowledged that while some stakeholders might be interested and keen to collect these data more frequently and / or at each healthcare encounter, to recommend more than an annual collection could be too prescriptive and burdensome for providers.

This was an ambitious project and the working group recognised that it was unlikely to satisfy everyone. This is however a good starting point and further outcome measures should be explored and developed for specific niche groups such as older people with frailty, cognitive impairment, physical disability as well as exploring outcome measures that would be relevant for carers and researchers in old age health. Furthermore as these outcome measures start being used, areas for improveing 
Table 5 Standard Set of Outcome Domains for Older People

\begin{tabular}{|c|c|c|c|}
\hline Tiers & Outcome Domains & Supporting Information & Suggested Data Sources \\
\hline \multirow[t]{3}{*}{ Tier 1} & Overall Survival & All cause survival & Administartive data \\
\hline & Place of Death & $\begin{array}{l}\text { Whether a preferred place to die has been expressed, the patient died } \\
\text { in their usual place of residence and whether they died in their preferred } \\
\text { place of death (if previously expressed) }\end{array}$ & Clinical data \\
\hline & Frailty & Tracked via the Canadian Study on Health \& Aging Clinical Frailty Scale & Clinical data \\
\hline \multirow[t]{4}{*}{ Tier 2} & Polypharmacy ${ }^{\text {S190-191 }}$ & $\begin{array}{l}\text { Includes the total number of prescribed medications, adverse drug events and whether } \\
\text { medications make the patient unwell }\end{array}$ & $\begin{array}{l}\text { Clinical data, Patient } \\
\text { reported }\end{array}$ \\
\hline & Falls $s^{5192}$ & $\begin{array}{l}\text { How many falls has the patient sustained in the last } 12 \text { months and how many falls } \\
\text { have resulted in a fracture, need for any professional medical attention and hospitalization }\end{array}$ & $\begin{array}{l}\text { Clinical data, Patient } \\
\text { reported }\end{array}$ \\
\hline & $\begin{array}{l}\text { Particiapation in } \\
\text { decision making }\end{array}$ & $\begin{array}{l}\text { Includes confidence in; ability to cope with own health, role as participant in } \\
\text { care (involved in discussions, planning) and healthcare professionals. Also includes } \\
\text { the experience of having been treated with dignity and respect, coordination of } \\
\text { care and discharge to place of choice }\end{array}$ & Patient reported \\
\hline & Time spent in hospital & Number of hospital admissions, readmissions and total time spent in hospital over a year & Administrative data \\
\hline \multirow[t]{6}{*}{ Tier 3} & $\begin{array}{l}\text { Loneliness and } \\
\text { isolation } 5193\end{array}$ & Tracked via the UCLA-3-item scale & Patient reported \\
\hline & $\begin{array}{l}\text { Activities of daily } \\
\text { living }\end{array}$ & $\begin{array}{l}\text { Includes mobility and limitations to activities of daily living and tracked via the } \\
\text { SF-36 and gait speed }\end{array}$ & $\begin{array}{l}\text { Clinical data, Patient } \\
\text { reported }\end{array}$ \\
\hline & Pain 196 & Tracked via the SF-36 & Patient reported \\
\hline & $\begin{array}{l}\text { Mood and } \\
\text { emotional health } \\
\text { S197 }\end{array}$ & Tracked via the SF-36 & Patient reported \\
\hline & $\begin{array}{l}\text { Autonomy and } \\
\text { control }^{\text {S198 }}\end{array}$ & $\begin{array}{l}\text { How much control the patient has over their daily life tracked via the Adult Social } \\
\text { Care Outcomes Toolkit }\end{array}$ & Patient reported \\
\hline & Carer burden ${ }^{5199}$ & Carer reported burden tracked via the 4-item screening Zarit Burden Interview & Carer reported \\
\hline
\end{tabular}

\section{Key to Table 5}

UCLA University of California, Los Angeles -3 Item Scale [59]

SF36 Short Form (36) Health Survey [60]

ASCOT Adult Social Care Outcomes Toolkit [61]

ZBI Zarit Burden Interview [62]

CSHACFS Canadian Study of Health and Ageing Clinical Frailty Scale [63]

Polypharmacy

S190. Tjia J, Velten SJ, Parsons C et al. Studies to reduce unnecessary medication use in frail older adults: a systematic review. Drugs Aging 2013;30(5):285-307

S191. Shrank WH, Polinski JM, Avorn J. Quality indicators for medication use in vulnerable elders. J Am Geriatr Soc 2007;55 Suppl 2: S373-82

Falls

S192. Chang JT, Ganz DA. Quality indicators for falls and mobility problems in vulnerable elders. J Am Geriatr Soc 2007;55 Suppl 2: S327-34

Loneliness and isolation

S193. Hughes ME, Waite $\sqcup$, Hawkley LC et al. A short scale for measuring loneliness in large surveys: Results from two population-based studies. Res Aging 2004;26(6):655-672

Activities of daily living

S194. 36-Item Short Form Survey (SF-36). Available at http://www.rand.org/health/surveys_tools/mos/36-item-short-form.html Accessed on the 13 November 2016 S7195. Peel NM, Kuys SS, Klein K. Gait speed as a measure in geriatric assessment in clinical settings: a systematic review. J Gerontol A Biol Sci Med Sci 2013;68(1):39-46 Pain

S196. 36-Item Short Form Survey (SF-36). Available at http://www.rand.org/health/surveys_tools/mos/36-item-short-form.html Accessed on the 13 November 2016 Mood and emotional health

S197. 36-Item Short Form Survey (SF-36). Available at: http://www.rand.org/health/surveys_tools/mos/36-item-short-form.html Accessed on the 13 November 2016 Autonomy and control

S198. Available at: http://www.pssru40.org.uk/ascot Accessed on the 13 November 2016

Carer burden

S199. Bedard M, Molloy DW, Squire L et al. The Zarit Burden Interview: a new short version and screening version. Gerontologist 2001;41: 652-657

them would arise and allow for them to be amended continuously to make them relevant and fit for purpose as our healthcare environment continues to change.

\section{Conclusion}

Through the efforts reported in this paper, the ICHOM older people working group defined a standard set of recommended outcome measures that matter to older people. This is a first effort towards a standardisation of outcome measures to improve the quality of care for older people. Much further work remains to be done but in the meantime, itwould be ideal for national data sets to include information which allows these outcomes to be derived routinely.

\section{Additional file}

Additional file 1: All the references cited in the Tables S1. (DOCX $72 \mathrm{~kb}$ ) 


\section{Abbreviations}

ASCOT: Adult social care outcomes toolkit; CSHACFS: Canadian study of health and ageing clinical frailty scale; ICHOM: International consortium for health outcomes measurement; OP: Older people; SF36: Short form (36) health survey; UCLA: University of California, Los Angeles; WG: Working Group; ZBI: Zarit burden interview

\section{Acknowledgments}

Matt Salt, BSC MPH, Standardisation Associate ICHOM.

For formatting the Tables and references.

\section{Funding}

NHS England funded ICHOM to carry out this study. NHS England as an organisation was not involved in the design of the study, collection, analysis, and interpretation of data and in writing the manuscript. However please note a representative DB was a member of the working group but the final outputs reflected the overall working group's views.

\section{Availability of data and materials}

The datasets generated and a reference guide are freely available on the ICHOM Older People website, http://www.ichom.org/medical-conditions/older-person/

\section{Authors' contributions}

AA - was involved in the study design, interpretation of data, drafting the manuscript and supervision. CR - was involved in the study design, interpretation of data, drafting the manuscript, obtaining funding, administrative support and supervision. KB was involved in the study design, interpretation of data and drafting the manuscript. BB was involved in the study design, interpretation of data and drafting the manuscript. CB was involved in the study design, interpretation of data and drafting the manuscript. DB was involved in the study design, interpretation of data and drafting the manuscript. JB was involved in the study design, interpretation of data and drafting the manuscript. IC was involved in the study design, interpretation of data and drafting the manuscript. LC was involved in the study design, interpretation of data and drafting the manuscript. AE was involved in the study design, interpretation of data and drafting the manuscript. AF was involved in the study design, interpretation of data and drafting the manuscript. TG was involved in the study design, interpretation of data, drafting the manuscript and obtaining funding. $\mathrm{MH}$ was involved in the study design, interpretation of data and drafting the manuscript. DH was involved in the study design, interpretation of data and drafting the manuscript. JH was involved in the study design, interpretation of data and drafting the manuscript. DRH was involved in the study design, interpretation of data and drafting the manuscript. HL was involved in the study design, interpretation of data, drafting the manuscript and obtaining funding. $J L$ was involved in the study design, interpretation of data and drafting the manuscript. MM was involved in the study design, interpretation of data and drafting the manuscript. RI was involved in the study design, interpretation of data, drafting the manuscript and obtaining funding. FMR was involved in the study design, interpretation of data and drafting the manuscript. SS was involved in the study design, interpretation of data and drafting the manuscript. JS was involved in the study design, interpretation of data and drafting the manuscript. CS was involved in the study design, interpretation of data and drafting the manuscript. SS was involved in the study design, interpretation of data and drafting the manuscript. GT was involved in the study design, interpretation of data, drafting the manuscript and obtaining funding. NV was involved in the study design, interpretation of data and drafting the manuscript. GJY was involved in the study design, interpretation of data and drafting the manuscript. JY was involved in the study design, interpretation of data, drafting the manuscript and administrative support. JB was involved in the study design, interpretation of data, drafting the manuscript, administrative support and supervision. There are no persons who contributed to the work reported in the manuscript who do not fulfil authorship criteria.All authors read and approved the final manuscript.

\section{Ethics approval and consent to participate}

This research did not require ethical approval in 2015 when this was done using the MRC ethics decision-assistance tool and complies with national guidelines of Health Research Authority at: https://www.hra.nhs.uk/planningand-improving-research/research-planning/access-study-support-advice-services/
Written consent to participate in the focus group was obtained.

\section{Consent for publication}

All authors have given their consent for this manuscript to be published.

\section{Competing interests}

AA - received a honorarium as a research fellow for ICHOM and paid travel/ accommodation/registration for ICHOM conference.

$\mathrm{CR}, \mathrm{KB}, \mathrm{BB}, \mathrm{CB}$ : declares that they have no competing interests.

$\mathrm{DB}$ reports her commercial contract role within strategic consultancy whose primary aim is to see outcomes used more frequently as the currency to improve value in the NHS. She is therefore contracted to work with various health economies, including for some that are working on contracts for older people. No other reported conflicts of interest.

DB: Representative of NHS England.

JB: No reported conflicts of interest.

IC: reports receiving salary support from the National Health and Medical Research Council of Australia. Member of the editorial board of BMC Geriatrics. LC: Member of the editorial board of BMC Geriatrics

$A E$, AF, TG, MH, DH, JH, RI, DRH, HL, JL, MM, FMR, SS, JS: declares that they have no competing interests.

CS reports receiving salary support from the National Health and Medical Research Council of Australia. No other reported conflicts of interest.

SS, GT, NV, GJY, JY, JB: declares that they have no competing interests.

\section{Publisher's Note}

Springer Nature remains neutral with regard to jurisdictional claims in published maps and institutional affiliations.

\section{Author details}

${ }^{1}$ Department of Medicine for the Elderly, Aintree University Hospital NHS Foundation Trust, Lower Lane, Liverpool L9 7AL, UK. ${ }^{2}$ International Consortium on Health Outcomes Measurement, London, UK. ${ }^{3}$ International Consortium on Health Outcomes Measurement, Cambridge, USA. ${ }^{4}$ Johns Hopkins Bloomberg School of Public Health, Johns Hopkins Older Americans Independence Center, Baltimore, USA. ${ }^{5}$ Oxfordshire Clinical Commissioning Group, Oxford, UK. 'LMU München, Munich University Hospital, Munich, Germany. ${ }^{7} \mathrm{COBIC}$, London, UK. ${ }^{8} \mathrm{NHS}$ England, London, UK. ${ }^{9}$ The Dartmouth Institute for Health Policy \& Clinical Practice, Lebanon, USA. ${ }^{10}$ John Walsh Centre for Rehabilitation Research, Sydney Medical School, University of Sydney, Sydney, Australia. ${ }^{11}$ Ageing and Health Research Center, National Yang Ming University, Taipei, Taiwan. ${ }^{12}$ Center for Geriatrics and Gerontology, Taipei Veterans General Hospital, Taipei, Taiwan. ${ }^{13}$ Section of Clinical Geriatrics, Department of Neurobiology, Care Sciences and Society, Karolinska Institute, Stockholm, Sweden. ${ }^{14}$ Cambridgeshire and Peterborough Clinical Commissioning Group, Cambridge, UK. ${ }^{15}$ AgeUK, London, UK.

${ }^{16}$ Havenziekenhuis, Rotterdam, Netherlands. ${ }^{17}$ Older Person representative, Kingston, Canada. ${ }^{18}$ Internal Medicine-Geriatrics, Faculty of Medicine, Universidad Peruana Cayetano Heredia, Lima, Peru. ${ }^{19}$ Altarum Institute, Ann Arbor, USA. ${ }^{20}$ University of Zurich, Zurich, Switzerland. ${ }^{21}$ Erasmus University Medical Center, Rotterdam, Netherlands. ${ }^{22}$ Sigma Theta Tau International Honor Society of Nursing, Indiana, USA. ${ }^{23}$ UCL Partners, London, UK. ${ }^{24}$ The George Institute for Global Health, University of Sydney, Sydney, Australia. ${ }^{25}$ Departments of Medicine, Family and Community Medicine and the Institute of Health Policy Management and Evaluation, University of Toronto, Toronto, Canada. ${ }^{26}$ Sinai Health System and University Health Network, Toronto, Canada. ${ }^{27}$ British Geriatrics Society, London, UK. ${ }^{28}$ University Nijmegen Medical Centre, Nijmegen, Netherlands. ${ }^{29}$ Family caregiver, Taipei, Taiwan. ${ }^{30}$ University of Leeds, Leeds, UK. ${ }^{31}$ University Hospitals of Leicester NHS Trust, Leicester, UK. ${ }^{32} \mathrm{NHS}$ Digital, Leeds, UK.

Received: 11 July 2017 Accepted: 29 December 2017

Published online: 02 February 2018

\section{References}

1. World health statistics 2016: monitoring health for the SDGs, sustainable development goals. Available at: http://apps.who.int/iris/ bitstream/10665/206498/1/9789241565264_eng.pdf?ua=1. Accessed 11 Oct 2017.

2. Banerjee S. Multimorbidity: older adults need health care that can count past one. Lancet. 2014;385:587-9. 
3. Oliver D, Foot C, Humphries R. Making our health and care systems fit for an ageing population. The King's Fund. Available at : http://www.kingsfund. org.uk/sites/files/kf/field/field_publication_file/making-health-care-systems-fitageing-population-oliver-foot-humphries-mar14.pdf. Accessed 01 Apr 2016.

4. Makary MA. How health care's successes became distractions. Health Affairs (Millwood). 2014;33:1311-3.

5. Drouin $\mathrm{H}$, Walker J, McNeil $\mathrm{H}$, et al. Measured outcomes of chronic care programs for older adults: a systematic review. BMC Geriatr. 2015;15:139-48.

6. ICHOM Standard Set. Available at: http://www.ichom.org/medical-conditions. Accessed 13 Apr 2016.

7. Boulkedid R, Abdoul H, Loustau M, et al. Using and reporting the Delphi method for selecting healthcare quality indicators: a systematic review. Wright JM, ed. PLoS One. 2011;6(6):e20476.

8. Liberati A, Altman DG, Tetzlaff J, et al. The PRISMA statement for reporting systematic reviews and meta-analyses of studies that evaluate healthcare interventions: explanation and elaboration. BMJ. 2009;339:b2700.

9. Taylor JO, Wallace RB, Ostfeld AM et al. Established Populations for Epidemiologic Studies of the Elderly, 1981-1993: [East Boston, Massachusetts, lowa and Washington Counties, lowa, New Haven, Connecticut, and North Central North Carolina] Inter-university Consortium for Political and Social Research (ICPSR). Available at: http://www.icpsr.umich.edu/icpsrweb/NACDA/studies/9915. Accessed 17 June 2016.

10. Baltimore Longitudinal Study on Aging. Available at: https://www.blsa.nih. gov. Accessed 17 June 2016.

11. Guralnik JM, Fried LP, Simonsick EM, et al. The Women's Health and Aging Study: Health and Social Characteristics of Older Women With Disability. Bethesda, MD: National Institute on Aging; 1995. NIH Publication 95-4009:009-018

12. Women's Health and Aging Study I (WHAS I). Available at: http://coah.jhu. edu/research/projects/whas_i.html. Accessed 17 June 2016.

13. Women's Health and Aging Study II(WHAS II). Available at: http://coah.jhu edu/research/projects/whas_ii.html. Accessed 17 June 2016.

14. Health, Aging and Body Composition Study. Available at: https://www.nia. nih.gov/research/intramural-research-program/dynamics-health-aging-andbody-composition-health-abc. Accessed 17 June 2016.

15. Cardiovascular Health Study. Available at: http://coah.jhu.edu/research/ projects/chs.html. Accessed 17 June 2016.

16. InCHIANTI study. Available at: http://inchiantistudy.net/wp/. Accessed 17 June 2016.

17. National Health and Aging Trends Study. Available at: http://www.nhats.org. Accessed 17 June 2016.

18. Canadian Longitudinal Study on Aging, the Health \& Retirement Study. Available at: https://www.clsa-elcv.ca. Accessed 14 Apr 2016.

19. Mexican Health and Aging Study (MHAS). Available at: http://www. mhasweb.org. Accessed 14 Apr 2016.

20. Costa Rican Study of Longevity and Healthy Aging. Available at: http:// www.creles.berkeley.edu. Accessed 15 Apr 2016.

21. Brazilian Longitudinal Study of Ageing and Wellbeing. Available at: http:// elsi.cpqrr.fiocruz.br/en/. Accessed 15 Apr 2016.

22. Puerto Rican Elderly: Health conditions (PREHCO). Available at: http://prehco. rcm.upr.edu. Accessed 15 Apr 2016.

23. The Irish Longitudinal Study on Ageing (TILDA). Available at: http://tilda.tcd. ie. Accessed 15 Apr 2016

24. Dublin Mid Leinster Minimum Dataset for Older People in Care Settings. Available at: https://www.hse.ie/eng/services/Publications/olderpeople/ dataset.html?pageNumber=348. Accessed 15 Apr 2016.

25. English Longitudinal Study of Ageing (ELSA). Available at: http://www.elsaproject.ac.uk. Accessed on the 15 Apr 2016.

26. NHS Benchmarking. National audit of intermediate care summary report 2015. Available at http://www.nhsbenchmarking.nhs.uk/CubeCore/.uploads/ NAIC/Reports/NAICReport2015FINALA4printableversion.pdf. Accessed 15 Apr 2016

27. Italian Longitudinal Study on Ageing (ILSA). Available at: http://www.alzrisk org/cohort.aspx?cohortid=53. Accessed 15 Apr 2016.

28. The Swedish National Study on Aging and Care in Kungsholmen (SNAC-K) Available at: http://www.snac-k.se. Accessed 15 Apr 2016

29. The Older Persons and Informal Caregivers Survey Minimal Dataset, Netherlands (TOPICS-MDS). Available at: http://topics-mds.eu. Accessed 15 Apr 2016.

30. National Care for the Elderly Programme, Netherlands (NCEP). Available at: http://www.beteroud.nl/ouderen. Accessed 15 Apr 2016.
31. Survey of Health, Ageing and Retirement in Europe (SHARE). Available at: http://www.share-project.org. Accessed 15 Apr 2016.

32. Longitudinal Ageing Study in India (LASI). Available at: http://iipsindia.org/ research lasi.htm. Accessed 15 Apr 2016.

33. China Health and Retirement Longitudinal Study (CHARLS). Available at: http://charls.ccer.edu.cn/en. Accessed 15 Apr 2016.

34. Korean Longitudinal Study of Ageing (KLoSA). Available at: http://www.kli.re. kr/kli/index.do. Accessed 15 Apr 2016.

35. Japanese Study of Ageing and Retirement (JSTAR). Available at: http://www. rieti.go.jp/en/projects/jstar/. Accessed 15 Apr 2016.

36. Taiwan Longitudinal Study on Aging (TLSA). Available at: http://www. hpa.gov.tw/English/ClassShow.aspx?No=200803270009. Accessed 15 Apr 2016.

37. Australian Dynamic Analyses to Optimise Ageing. Available at: http:// dynopta.anu.edu.au. Accessed Apr 2016

38. WHO Study on global ageing and adult health (SAGE). Available at: http:// www.who.int/healthinfo/sage/en/. Accessed 15 Apr 2016.

39. Porter ME. What is value in health care? N Engl J Med. 2010;363:2477-81.

40. Global Agewatch index Life expectancy at 60. 2015. Available at: http:// www.helpage.org/global-agewatch/population-ageing-data/life-expectancyat-60/. Accessed 13 Apr 2016.

41. United Nations World Population Ageing 2013. Department of Economic and Social Affairs, Population Division. Available at: http://www.un.org/en/ development/desa/population/publications/pdf/ageing/ WorldPopulationAgeing2013.pdf. Accessed 13 Apr 2016.

42. WHO and UN. Ageing and Life Course. Available at: http://www.who.int/ ageing/en/. Accessed 13 Apr 2016.

43. Roebuck J. When does old age begin?: the evolution of the English definition. J Soc Hist. 1979;12(3):416-28. Available at: http://jsh. oxfordjournals.org/content/12/3/416.full.pdf+html. Accessed 13 Apr 2016

44. Miner $\mathrm{L}$, Bolding $\mathrm{P}$, Hillbe $\mathrm{J}$ et al. Practical predictive analytics and Decisioning Systems for Medicine, 1st Edition. London: Elsevier; 2014.

45. O'Malley AJ, Zaslavsky AM, Elliott MN, Zaborski L, Cleary PD. Case-mix adjustment of the CAHPS ${ }^{\circledR}$ hospital survey. Health Serv Res. 2005:40:2162-81.

46. UNESCO. International Standard Classification of education ISCED 2011. Available at: http://www.uis.unesco.org/Education/Documents/isced-2011en.pdf. Accessed 14 Apr 2016.

47. Allsop J. Competing Paradigms and Health Research: Design and Process. In Researching Health: Qualitative, quantitative and mixed methods. $2^{\text {nd }}$ edition. Saks M \& Allsop J (Eds). Thousand Oaks: Sage Publications; 2013.

48. Bandeen-Roche K, Xue Q, Ferrucci L, et al. Phenotype of frailty: characterization in the Women's health and aging studies. J Gerontol Ser A Biol Med Sci. 2006;61:262-6.

49. Clegg A, Young J, Iliffe S. Frailty in elderly people. Lancet. 2013;381: 752-62.

50. Turner G, Clegg A. Best practice guidelines for the management of frailty: a British geriatrics society, age UK and Royal College of general practitioners report. Age Ageing. 2014;43:744-7.

51 Morley JE, Vellas B, van Kan GA, et al. Frailty consensus: a call to action. J Am Med Dir Assoc. 2013;14:392-7.

52. Ko FC, Walston JD.What is frailty? In: Evidenced based practice in palliative medicine Goldstein NE \& Morrison S (Eds). Philadelphia: Elsevier; 2013. Chap 63 pg. 363-70.

53. Fried LP, Tangen CM, Walston J, et al. Frailty in older adults: evidence for a phenotype Gerontol a biol Sci. Med Sci. 2001:56(3):M146-56.

54. Jones DM, Song X, Rockwood K. Operationalizing a frailty index from a standardized comprehensive geriatric assessment. J Am Geriatr Soc. 2004:52(11):1929-33.

55. de Vries NM, Staal JB, Olde MG, et al. Evaluative frailty index for physical activity (EFIP): a reliable and valid instrument to measure changes in level of frailty. Phys Ther. 2013;93:551-61.

56. Moorhouse IP, Rockwood K. Frailty and its quantitative clinical evaluation. JR Coll Physicians Edinb. 2012:42:333-4

57. Song X, Mitnitski A, Rockwood K. Prevalence and 10-year outcomes of frailty in older adults in relation to deficit accumulation. J Am Geriatr Soc. 2010;58:681-7.

58. Clegg A, Bates C, Young J, et al. Development and validation of an electronic frailty index using routine primary care electronic health record data. Age Ageing. 2016;0:1-8

59. Russell D. UCLA loneliness scale (version 3): reliability, validity, and factor structure. J Pers Assess. 1996;66:20-40. 
60. Ware JE, Sherbourne CD. The MOS 36-item short-form health survey (SF-36): conceptual framework and item selection. Med Care. 1992;30:473-83.

61. Netten A, Forder J, Beadle-Brown J, et al. Adult Social Care Outcomes Toolkit Version 1.0 (ASCOT). Discussion Paper No. 2716, Personal Social Services Research Unit, University of Kent, Canterbury; 2010.

62. Zarit SH, Orr NK, Zarit JM. The hidden victims of Alzheimer's disease. New York: Families under stress New York University Press; 1985.

63. Rockwood $K$, Song $X$, Macknight $C$, et al. A global clinical measure of fitness and frailty in elderly people. CMAJ. 2005;173:489-95.

Submit your next manuscript to BioMed Central and we will help you at every step:

- We accept pre-submission inquiries

- Our selector tool helps you to find the most relevant journal

- We provide round the clock customer support

- Convenient online submission

- Thorough peer review

- Inclusion in PubMed and all major indexing services

- Maximum visibility for your research

Submit your manuscript at www.biomedcentral.com/submit 